\title{
On Who Matters: Extending the Scope of Luck Egalitarianism to Groups
}

Sara Amighetti (University of Zurich) and Siba Harb (KU Leuven)

\subsection{Introduction}

In this contribution we discuss Chapter 6 of Kasper LippertRasmussen's new book, where he treats the question of the scope of luck egalitarianism (hence-forth LE). We will focus on the only dimension for which he defends a narrow version of the scope of LE. When it comes to asking whether the scope of LE extends beyond individuals to include groups, Lippert-Rasmussen's categorical answer is that, as egalitarians, we should be concerned only with inequality between individuals and only when that inequality is not the result of choices that can be traced back to individuals. We disagree that this is the only plausible interpretation of the scope of LE and argue that Lippert-Rasmussen is mistaken about the considerations that settle the question of scope at hand. His view risks neglecting important concerns of egalitarian justice since there are good reasons to think that (a) inequality between groups matters, and that (b) groups can make choices which are relevant from a luck egalitarian perspective.

Our discussion unfolds as follows: we first reconstruct and interpret Lippert-Rasmussen's arguments for restricting the scope of LE to individuals. We then give an account of how inequality between groups matters and explain the importance of making LE sensitive to 
corporate choice. We conclude by suggesting possible implications of our arguments for the debate on global justice.

\subsection{The Scope of LE According to Lippert-Rasmussen}

Let us start by stating what Lippert-Rasmussen (2015) takes to be the canonical formulation of the LE principle:

"It is unjust if some people are worse off than others through their bad luck.” (p. 161)

Noting that the scope of the principle is left undetermined, Lippert-Rasmussen argues that we should understand it as extending to include individuals' whole lives, past and future generations, all individuals in the world, as well as non-human animals. In this contribution we are interested in discussing his treatment of the further question of whether the scope of LE is limited to comparisons between individuals or whether the principle also applies to comparisons between groups.

Before we engage with his argument, we should point out that the LE principle, as formulated above, comprises two distinct claims. The first (a) is an equality-claim, which says that the appropriate distributive baseline for the relevant distribuenda is egalitarian; the second (b) is a luckist-claim specifying that deviations from the egalitarian baseline established by (a) are unjust if they are the result of bad luck (however understood). ${ }^{1}$ Lippert-Rasmussen (2015)

\footnotetext{
${ }^{1}$ Richard Arneson similarly breaks LE down into 'egalitarianism' and 'luckism'; he further highlights that while the two claims should be understood as working 'in
} 
discusses the application of the principle to groups in relation to each: (i) by asking whether our concern with inequality applies to distributions between individuals or between groups and (ii) by asking whose choice (individuals or groups) is relevant when identifying unjust deviations from the baseline (p. 161).

\subsubsection{The Scope of the Equality-Claim}

Does our concern with inequality (i.e., the presumption of equality in the equality-claim) apply to distributions between individuals, groups, or both? Lippert-Rasmussen's (2015) answer is that luck egalitarians should be concerned with inequality between individuals and individuals only. He argues that group inequality does not matter either alone or in addition to individual inequality (p. 162). We begin by examining his reasons against an exclusive concern with group inequality, since doing so will also allow us to make explicit some important yet hidden premises of the argument. According to LippertRasmussen, an exclusive concern with group inequality commits us to conclusions we would not be willing to accept, and he illustrates this point with the following example. Suppose that men and women were the only relevant groups in which a given population could be divided and imagine the following two distributions of a relevant good between the two groups (see Table 1). In scenario 1, all the men have 100 units of the good and all the women have 50 . In scenario 2 , half of the men have 200 while the other half has 0 , and the same goes for the women.

tandem,' recognizing that each claim comes in different versions is crucial to "identify the most plausible and promising combination of them" (2012, p. 72). 
Lippert-Rasmussen argues that if we were only concerned with groups, we would regard scenario 2 as preferable from the point of view of justice because, unlike scenario 1 , it has no inequality between men and women. We can see this when we compare the groupaverages, which are what Lippert-Rasmussen takes to be the relevant indicator of group-inequality (2011, 2013, 2015, p. 162). In scenario 1, men as a group (M1) have on average 100 units and women (W1) have 50; in scenario 2, men as a group (M2) have 100 and women (W2) have 100. So, if we only compared group-levels, we would have to say that scenario 2, where $\mathrm{M} 2=\mathrm{W} 2$, is more just than scenario 1, where M1 > $\mathrm{W} 1$. However, this would be a problematic conclusion to draw because scenario 2 contains serious intra-group inequality, while scenario 1 has none.

Table 1. Exclusive Concern with group-inequality vs individual-inequality according to Lippert-Rasmussen

\begin{tabular}{cccc}
\hline \multicolumn{2}{c}{ Scenario 1 } & \multicolumn{3}{c}{ Scenario 2 } \\
\hline $\mathrm{M}_{1}$ & $\mathrm{~W}_{1}$ & $\mathrm{M}_{2}$ & $\mathrm{~W}_{2}$ \\
\hline 100 & 50 & 200 & 200 \\
100 & 50 & 0 & 0 \\
\hline
\end{tabular}

Having argued that group inequality cannot matter exclusively, Lippert-Rasmussen (2015) further submits that it cannot matter in addition to inequality between individuals. He thinks that this is so because when a trade-off arises between greater individual equality and greater group equality, we would not opt for increasing equality 
between groups at the expense of increasing inequality between individuals (2015, pp. 162, 163). Accordingly, Lippert-Rasmussen concludes that group inequality can only matter instrumentally, meaning that reducing it is often a proxy for reducing individual inequality. We believe that Lippert-Rasmussen draws this conclusion too quickly, and we will show below that his discussion fails to consider possible reasons for thinking that group inequality is problematic justice-wise.

Before turning our attention to that, let us make a brief critical observation with regard to the way in which he constructs the argument. As seen, he shows that focusing on group inequality would lead us to either ignore inequality between individuals or increase it; by suggesting that these are both implausible options, he concludes that the scope of the equality-claim must be limited to individuals. However, his discussion of the scope does not make it clear what warrants such a conclusion. To understand why Lippert-Rasmussen thinks that it is unjust to treat individuals unequally, but not unjust to treat groups unequally, one needs to go back to his discussion of moral equality in Chapter 2. There, he argues that the equality-claim holds between those who are morally equal because it would be unfair to treat those with equal moral standing unequally (2015, pp. 51-54). He also explains that the feature according to which we can attribute equal moral standing is the "capacity for caring non-instrumentally about things in a distinctive way" (2015, p. 54). Arguably, this capacity is 
possessed only by individuals (and not by groups), ${ }^{2}$ and we think this is what grounds Lippert-Rasmussen's assumption that only individuals can be the relevant subjects of the equality-claim. Since groups lack any independent moral status, there is no principled way to demand that they be treated equally, such that an equal distribution of $\mathrm{X}$ is appropriate between them.

Reconstructing Lippert-Rasmussen's argument as above-by disentangling the claim about moral equality from that about distributive equality — is important for our argument. To anticipate, we will side with Lippert-Rasmussen and endorse the view that groups, unlike individuals, do not have independent moral status, ${ }^{3}$ but we will reject his conclusion that this is the reason why groups are excluded from the scope of the LE principle. We will argue instead that egalitarian justice can nevertheless require an equal distribution of certain goods between groups.

\subsubsection{The Scope of the Luckist-Claim}

Having narrowed the scope of the equality-claim to individuals, Lippert-Rasmussen turns to discuss the scope of the luckist-claim,

\footnotetext{
${ }^{2}$ However, see Collins and Lawford-Smith (2016, p. 51) for the view that groups can value things non-instrumentally (having non-instrumentally valuable relations with their members).

${ }^{3}$ An argument that (certain) groups may possess independent moral standing, such that they could be regarded as moral equals, would also challenge LippertRasmussen's individualistic restriction since it is unjust to treat moral equals unequally. We do not wish to pursue this argumentative strategy, because, like him, we work within the framework of normative individualism (i.e., the view that individuals are the ultimate units of moral concern). For reasons to be normative individualists see List and Pettit (2011, chap. 8). We thank an anonymous reviewer for asking us to be explicit about this.
} 
which specifies that inequality resulting from bad luck is unjust. As Lippert-Rasmussen notes, the claim is ambiguous with respect to whose luck we ought to take into consideration (2011, 2015, pp. 163165). Given that individuals do not make choices only on their own, we should ask whether the luckist-claim applies exclusively to each individual's choice or whether it includes group choice, too. ${ }^{4}$ Once again, Lippert-Rasmussen (2015) resolves this ambiguity in favor of individuals, arguing that only individual choice "undermines luck" (p. 161). In particular, he defends an interpretation of the luckist-claim according to which an outcome is a matter of bad luck for an individual if and only if it is not the result of that individual's choice (LippertRasmussen, 2009, 2011, 2015, pp. 163-165). He finds assigning significance to group choice problematic because "group choice is beyond the control of its individual members" and, as a result, it has "a more problematic relation to luck than individual choice” (2015, p. 165). The idea here seems to be that a principle of justice is undesirable (unfair) if it makes individuals bear the consequences of choices over which they lack full control.

As before, we will raise doubts about the validity of restricting the luckist-claim to individual choices. Although Lippert-Rasmussen's argument is more nuanced than we have presented it here, this brief summary suffices for our purposes, for we will argue that by neglecting corporate choice, he thinks about group choice too narrowly.

\footnotetext{
${ }^{4}$ For now, we use the term group-choice with no further specification to refer to a range of possible understandings of a choice made collectively. We will present and defend one such understanding in Section 4.4.
} 
To recap, for Lippert-Rasmussen neither group inequality nor group choice matter from the point of view of LE justice. The scope of $\mathrm{LE}$ as regards the individual/collective dimension is restricted to individuals only. In the next two sections, we will critically evaluate his individualistic interpretation of the two claims forming the LE principle. We will focus on each claim in turn with the aim of bringing to the forefront considerations about the relevance of groups that Lippert-Rasmussen omitted and which have significant implications for determining the scope of the LE principle in other debates (e.g., global justice) as well.

\subsection{The Scope of the Equality-Claim Revisited}

Let us begin with the equality-claim. We will argue that egalitarians like Lippert-Rasmussen have good reasons to be concerned with distributive inequality between groups in addition to inequality between individuals. More specifically, we think that when a particular class of goods is considered, justice requires such goods to be distributed equally among the relevant groups.

Our argument proceeds as follows: we first suggest that within Lippert-Rasmussen's favored account of the metric of distributive equality, it is possible to identify the category of collective goods, which we define as goods that individuals can hold only together with others (as a group). If collective goods count as distribuenda, it follows from the equality-claim that they should be distributed equally between groups. The reason for this is simple: the nature of collective goods is 
such that if we want to distribute them equally, we ought to distribute them between groups.

While this argument is sufficient to challenge LippertRasmussen's restriction of the equality-claim to individuals, we also offer a second argument where we relax our assumption that collective goods count as distribuenda. As it will become clear, even in this case, Lippert-Rasmussen's case for limiting the scope of distributive equality to individuals is undermined.

\subsubsection{Aggregative Goods and Collective Goods}

Lippert-Rasmussen (2015) tells us in Chapter 4 that people should be equal in terms of "that which they care about non-instrumentally and not unreasonably so" (p. 112). We think that this account of the metric of equality is broad enough to include at least two distinct types of goods: (i) goods that individuals hold (or enjoy) separately, i.e., individually and (ii) goods which can only be held (or enjoyed) jointly by a set of individuals, i.e., collectively.

Although Lippert-Rasmussen does not discuss this distinction, it is worth noticing that when he addresses the scope of the equalityclaim, asking whether the goods that matter for justice should be distributed between individuals or groups, he has in mind only the first category of goods identified above. This becomes clear from the examples he uses - all involving goods such as income, wealth, or health - and of how he accounts for the distribution of such goods at the group-level. For example, to compare how women and men as groups fare in terms of health, he uses the average health-level of the 
two groups (2013, pp. 52-65; 2015, p. 162). However, this averaging strategy makes sense only if the goods in question can be possessed individually, and such goods are the same good at the individual and group-level. In other words, the nature of these goods must be aggregative. While it is possible that most of the goods we care about from the point of view of equality are aggregative, it is unlikely that all of them will be; for example, we would hesitate to classify language or religion as aggregative goods. As anticipated, we think there is a second category of goods that could qualify as the object of egalitarian distributions. We will now focus on these goods, explaining more precisely what they are and showing why taking them into account gives us reason to extend the scope of the equality-claim to groups.

Until now, we have provided only a working definition of collective goods, according to which they are goods that can only be held together with others. But how are we to understand this jointholding condition? And why does it justify the introduction of a new category of goods altogether? After all, wouldn't it be possible to say that if I hold a good and you hold a good, the group formed by the two of us has that good (my good and yours put together)? In light of these concerns, we should clarify that the condition of being jointly held by the group means that the individuals comprising the group possess a good together that none of them possesses separately. ${ }^{5}$ This suggests that it is their coming together which creates the good itself or the possibility of holding the good and determines the conditions of its

\footnotetext{
${ }^{5}$ The same idea can be found in Peter Jones's definition of the collective account of group rights (1999, pp. 83-86; 2014, pp. 52-72).
} 
enjoyment. Jeremy Waldron (1993) proposes to think of the good of conviviality at a party as an instance of collective good, in the sense that

its enjoyment is primarily a property of the group rather than of each of the individual guests considered by himself. . . . Conviviality or good atmosphere is a good experienced as such by people to the extent that they are participant members of a group to which the benefit of the good accrues at a collective level. (p. 335)

This example shows that the nature of these goods is genuinely collective in the sense that they exist only at the group-level; they do not result from the aggregation of a good that the individuals who make up the group hold severally, nor can they be disaggregated into goods that individuals hold in separation from others. Note, further, that to say a collective good is a good enjoyed by the group does not require making any controversial claims about the metaphysical or moral status of the group. We do not need to attribute any conscious state to the group as such or imply that the group acquires a moral standing that is independent from the moral standing of each of its individual members.

\subsubsection{Collective Goods as Distribuenda}

With a better understanding of collective goods, we now consider what follows from acknowledging them as distribuenda. One immediate consequence is that it is no longer obvious that group inequality cannot matter. To recall, Lippert-Rasmussen's argument for denying a concern with inequality between groups is that we would want to settle 
any possible trade-offs between reducing inter-group or intra-group inequality in favor of individuals, such that group-inequality would be unproblematic (when not redundant). However, when it comes to collective goods no similar trade-off arises, and Lippert-Rasmussen's reasoning for restricting the scope of the equality claim to individuals no longer applies. This is because one can only meaningfully talk about those goods in relation to groups and capture the corresponding inequality only at the group-level. More positively, this means that any egalitarian baseline with regard to such goods will only be conceivable as an equal distribution between groups.

Let us apply this argument to a politically relevant instance of collective goods by focusing on the good of self-determination enjoyed by a political community. ${ }^{6}$ There are two meanings of the term depending on the perspective one adopts; internally, it corresponds to the good that the individuals forming a political community possess together when they themselves choose, control, and participate in governing their affairs. ${ }^{7}$ Externally, it refers to the absence from external government (e.g., colonial rule) or intervention in the affairs

\footnotetext{
${ }^{6}$ Our argument would seem to apply to the collective goods mentioned before, such as conviviality, language, or religion. That said, we leave the question of which collective goods satisfy the conditions required by Lippert-Rasmussen's account of the currency of equality for another day. Here, we consider democratic selfdetermination a good that individuals value non-instrumentally and not unreasonably so. See Section 4.3.3 for a more detailed discussion.

${ }^{7}$ In this paper, we assume that (internal) self-determination requires democracy. Relaxing this assumption would create possible mismatches between internal and external understandings of self-determination, which we do not have the space to address. The democratic requirement has the advantage of making it clear that if we have non-instrumental reasons to value internal self-determination, then the same reasons commit us to value it externally.
} 
of a political community. What matters most to us here is that, on either of these meanings, democratic self-determination counts as a collective good; it is a good that any particular individual can possess only along with others, as a group. This makes collective self-determination different both from individual autonomy, i.e., the freedom to determine one's own life and goals, and from non-interference in the private affairs of the individual. These are also goods individuals value (and often for similar and overlapping reasons), but they are not the same good as collective self-determination. The point becomes even more apparent if we think that it would be odd to refer to collective selfdetermination as nothing more than the sum of individuals' level of autonomy, or to say that a political community is free as the result of its individual members being free from external interference in their private affairs. For self-determination to be a good in either sense (internally or externally), it must be a good that individuals enjoy only together with others.

Suppose now that democratic self-determination is noninstrumentally valuable to individuals. As egalitarians we would want each individual to enjoy self-determination equally, such that - absent considerations of differential responsibility — an equal distribution of it would apply between them. However, to say this would be a mistake. Because self-determination is a collective good and its enjoyment is only available to individuals at the group-level, an equal distribution of it can only mean an equal distribution between political communities. A world order where one political community A was less selfdetermining than another $\mathrm{B}$, perhaps because a natural disaster made it 
more vulnerable to B's external interference, would thus count as being unjustly worse off.

Attempts to redescribe such inequality at the individual level, for example by saying that an individual belonging to A has less selfdetermination than an individual belonging to $\mathrm{B}$, are flawed. The reason for this lies in the fact that it makes little sense to try to reduce political self-determination to a good that individuals hold separately, like individual autonomy. As already noticed above, individual autonomy is not the same type of good as collective self-determination, so to capture the inequality with respect to the latter good, we would have to extend the scope of our egalitarian concern to groups or, in this case, to political communities.

Our conclusion would seem to hold even if a critic insisted on assessing the situation in individualistic terms and suggested to specify the relevant good as 'membership to a political community that is selfdetermining' such that two individuals would be unequal if one belonged to a self-determining community and the other did not. ${ }^{8}$ In response, it is unclear to us what the introduction of membership is meant to establish. To reiterate, our argument develops from the idea that collective goods which individuals value for non-instrumental reasons ought to be distributed equally between groups. ${ }^{9}$ This follows from Lippert-Rasmussen's premise that the metric of distributive

\footnotetext{
${ }^{8}$ We thank the editors and an anonymous reviewer for pressing us to address this worry.

${ }^{9}$ Absent considerations about luck, which we take up in the discussion of the luckistclaim.
} 
justice includes all those things that individuals care about noninstrumentally combined with our claim that collective goods, given their nature, can only be distributed between groups. Membership in a self-determining community is valuable insofar as collective selfdetermination is valuable and not the other way around. If we are right about this, then collective self-determination is the relevant good that individuals care about non-instrumentally, hence the good that ought to be equally distributed (between groups).

In a moment we will discuss the possibility that selfdetermination, or other instances of collective goods, may not be valued non-instrumentally so as to satisfy Lippert-Rasmussen's currency conditions. For now, let us recap the implications of our argument based on the assumption that (some) collective goods will be part of the distribuenda. One such implication is that relying on an argument about moral equality alone, as Lippert-Rasmussen does, is insufficient to restrict concerns about distributive (in)equality to individuals. A more promising strategy to address the question of scope is to engage in a discussion about the currency of equality. This is what we have done in this section: when it is acknowledged that (some) collective goods are part of the currency, then groups can no longer be excluded from the scope of the equality-claim, meaning that intergroup inequality does not matter only instrumentally. 


\subsubsection{Further Considerations About Groups and the Scope of}

\section{Egalitarian Distributions}

Our critique of Lippert-Rasmussen has thus far relied on a conditional argument: if a collective good counts as distribuendum, then the equality-claim demands that it be equally distributed between groups. Assuming that self-determination represents a plausible instance of collective good that is of non-instrumental value to individuals, we have used this example to illustrate what kind of consequences follow from it for the scope of the equality-claim.

But suppose now that one believed there is nothing noninstrumentally valuable about collective self-determination, and that it is only valued to the extent that it creates valuable contexts of choice and interaction for individuals. In short, imagine that one were to reject the assumption that individuals care about collective goods in a noninstrumental way. To admit of this possibility is paramount to exclude collective goods like self-determination from the distribuenda, with the consequence that our critique of Lippert-Rasmussen would lose much of its force. Here, we address such a concern and dismiss its implications for our argument. ${ }^{10}$

In particular, we think that even under the new assumption that only individual/aggregative goods can be valued non-instrumentally, distributive equality among groups would still be required when it was true that:

\footnotetext{
${ }^{10}$ Note that in addition to helping us elaborate the argument, the discussion we provide below, in fact, lends further support to our claim that the question of scope is best settled through engagement with the currency of distributive equality.
} 
(a) Individuals value a good X non-instrumentally, and

(b) An equal distribution between groups of collective good $\mathrm{Y}$ was necessary for the equal distribution of good $\mathrm{X}$ between individuals.

Note that (a) corresponds to the equality-claim according to Lippert-Rasmussen's reading of it, given that good X, i.e., the distribuendum, is an aggregative good ex hypothesi. Because of condition (b), however, making individuals equal in terms of $\mathrm{X}$ requires collective good $\mathrm{Y}$ to be distributed equally, which in turn requires distributive equality between groups.

Let us illustrate with an example. Suppose, with republicans, that individuals have sound non-instrumental reasons to value being free from domination ${ }^{11}$; this makes individual freedom from domination our egalitarian distribuendum. Republicans think that making individuals equal in this respect, requires (primarily) an equal distribution of political power among them such as that which is realized in a democratic polity, a republic. However, a republic that was dominated by some external actor could not secure the conditions for individuals to be free. Therefore, neutralizing domination between individuals requires the political communities they form to be equally free from domination, as well. Such a requirement ought to be

\footnotetext{
${ }^{11}$ We will greatly simplify the argument; for a more sophisticated discussion see Laborde and Ronzoni (2016, pp. 283-293).
} 
understood (primarily) as demanding an equal distribution of political power between republics, similar to that which is realized by an equal distribution of (external) self-determination between them.

At this point, however, the reader may wonder how our position with regard to these cases-viz., cases where collective goods are not part of the metric of equality but their equal distribution is necessary for an equal distribution of aggregative goods that are part of the metric - differs from Lippert-Rasmussen's. After all, he is prepared to accept that inter-group equality matters instrumentally (LippertRasmussen, 2015, pp. 162, 163). By this, he could mean that equality between groups is (contingently) the best or most efficient way to achieve equality between individuals, or he could also mean the stronger claim that equality between groups is in fact a necessary (noncontingent) mean to achieve equality between individuals across groups. ${ }^{12}$ Note, however, that, in presenting our argument, we have hinted at a different way of understanding the relation of groupequality with equality between individuals. ${ }^{13}$ As our example above suggests, the necessary relationship we have in mind can be described

\footnotetext{
${ }^{12}$ A different, though still instrumental, understanding of the relationship between group (in)equality and individual (in)equality is offered by Young (2002), according to whom inter-group inequality allows us to identify structural injustice. On her view, group inequality matters because it is only by comparing groups that we are able to discern some injustices at the individual level, to wit, injustices that result from membership in structural groups. We raise this point here because we think that Young's claim is pertinent even (if not especially) for luck egalitarians, and because we worry she is often misread by them. She argues that if we disregard group inequality and focus on individual inequality only, we risk mistakenly attributing many individual inequalities to choice rather than luck (circumstance), thereby overlooking important injustices.

${ }^{13} \mathrm{We}$ thank an anonymous reviewer for pressing us to add this clarification.
} 
in non-instrumental terms if the distribution of collective good $\mathrm{Y}$ provides an existence condition for the distribution of good $\mathrm{X}$ or if it is constitutive of it. ${ }^{14}$ In other words, when the way in which we distribute good Y determines how we can distribute good $\mathrm{X}$ - as in cases where inequality in the distribution of collective good $\mathrm{Y}$ almost always leads to inequality in the distribution of $\mathrm{X}$, and improving equality in the distribution of $\mathrm{Y}$ almost always leads to improving equality in the distribution of $\mathrm{X}$ - then there is a relationship of necessity that is noninstrumental. ${ }^{15}$

\subsection{The Scope of the Luckist-Claim Revisited}

Building on our argument for applying the equality-claim to distributions between groups, in this section, we explore the scope of the luckist-claim. We ask: when justice requires a baseline of equality between groups, which deviations from it are unjust? According to LE's rationale, the answer is deviations that are the result of bad luck are not just. But this brings us back to the ambiguity noted earlier; if bad luck is understood as absence of choice, whose choice is relevant when talking about permissible inequality-individual or group choice, or maybe both? ${ }^{16}$

\footnotetext{
${ }^{14}$ We take the terminology from Abizadeh (2007, p. 324).

15 The relation of necessity we describe here is similar to that which O'Neill (2008) draws between distributive equality and relational equality, and which he uses to characterize his non-intrinsic egalitarianism.

16 While being aware of the important distinction made between choice and responsibility, we use the two terms interchangeably.
} 
Our argument for the extension of the scope of the luckist-claim to group-choice relies on a distinction to be made between two accounts of it. The first is the one Lippert-Rasmussen employs in his discussion, and it understands group-choice as nothing more than the aggregation of the choices individuals in the group make (aggregate choice). As mentioned, Lippert-Rasmussen thinks LE should be insensitive to group-choice understood in this way, and we grant that. However, there is a second account, in which group-choice is understood more holistically as a choice of the group qua group, and it is therefore not immediately reducible to the choices of its individual members. This account of group-choice (corporate choice) develops from a growing literature about group-agency ${ }^{17}$ according to which some groups (e.g., universities, firms, states) can be regarded as agents capable of forming beliefs, preferences, and intentions, and of acting upon them. Important, for our purposes, is the idea that to count as agents, these groups only need to satisfy weak functional criteriasuch as having an internal organizational structure for decisionmaking - the satisfaction of which does not entail the attribution of any metaphysical or moral status to the group-agent (List \& Pettit, 2011, chap. 7). The advantage of considering corporate choice is that it allows us to have a fuller picture of responsibility for outcomes. Indeed, there are cases in which looking at individual and aggregate responsibility could prove unsatisfactory because the outcome cannot be traced back solely to individual action but results from action

\footnotetext{
${ }^{17}$ See, among others, List and Pettit (2011).
} 
coordinated through structures and procedures of decision-making responsibility, which cannot be immediately attributed to a single individual or group of individuals. ${ }^{18}$

With the two accounts of group-choice distinguished, we can now see that the ambiguity in the luckist-claim involves three possibilities, instead of two: (i) individual choice, (ii) aggregate choice, and (iii) corporate choice. The question then becomes which of them makes inequality between groups permissible from an LE perspective.

Imagine that two groups $\mathrm{A}$ and $\mathrm{B}$, formed respectively by members $(\mathrm{a} 1 ; \mathrm{a} 2)$ and $(\mathrm{b} 1 ; \mathrm{b} 2)$ are unequal $(\mathrm{A}<\mathrm{B})$ with respect to a collective good X that matters for justice. According to (i), if A has less than B because of choices made by a1 and a2, such that it is true of the choice of each that it made A worse off, it would seem that the inequality between $\mathrm{A}$ and $\mathrm{B}$ is not unjust ( $\mathrm{a} 1$ and $\mathrm{a} 2$ have no complaints against b1 and b2).

What if we assess the situation according to (ii)? Suppose a1 and a2 made choices that, if taken separately, would not have resulted in A being made worse off but when aggregated have such a result. Here, we draw the same conclusions as Lippert-Rasmussen's when he discusses the parallel case of individual inequality; inequality resulting from aggregate group-choice over which individuals have no control is bad luck, hence unjust. To illustrate, suppose that (external) selfdetermination varies with population-size; the larger the population, the higher the capacity of a community to self-determine. Suppose,

\footnotetext{
${ }^{18}$ See List and Pettit (2011) for an example of this type of situation, and the related claim that neglecting corporate responsibility amounts to an injustice (p. 167).
} 
further, that the population of a certain community dwindles over time because of a low reproduction-rate ultimately leading that community to have less capacity for self-determination than another. In this example, the outcome should be considered as a matter of bad luck for the group. ${ }^{19}$

Our assessment of injustice becomes more complicated when we employ (iii). To see how, imagine that this time A and B meet the criteria of group-agency, such that it can be said that A's being worse off than B results from A's corporate choice. Is this inequality unjust? It depends. If we took the group-agents A and B to also be moral agents, we would say the inequality is not unjust because it resulted from A's choice. This follows from LE's rationale according to which a state of affairs where those with equal moral standing are unequally well off for reasons not related to the exercise of choice is unfair (Lippert-Rasmussen, 2015, pp. 48-49). However, we have not justified distributive equality between groups in terms of their equal moral standing, so it would be a mistake to apply LE's rationale in such a straightforward manner here.

Alternatively, we should look for a connection between the corporate choice and the individual members of the corporation. It is important that this connection not be one of simple reduction to individual choice, for that would mean collapsing the two accounts of corporate and aggregate choice, making LE between groups insensitive to both types of group-choice. Note, however, that the account of

\footnotetext{
19 De Schutter and Ypi (2012) discuss a similar situation in relation to linguistic groups and rights.
} 
corporate choice allows for a two-tier distribution of responsibility, whereby we first assign responsibility to the group, and only then (if at all) we distribute the ensuing liability to its individual members (List \& Pettit, 2011, pp. 163-169; Pasternak, 2013). This two-tier distribution allows attributing responsibility to individual members not on account of their control over the outcome, but because of a particular connection they have to the outcome or to the agent bringing about the outcome that justifies assigning responsibility to them. A relationship of authorization is one such connection ${ }^{20}$; an agent A who authorizes an agent $\mathrm{B}$ to act in her name may be held liable for outcomes brought about by B when B is not in a position to shoulder the burden. ${ }^{21}$

Although a discussion of the conditions for distributing liability onto group members is intricate, and well beyond the scope of this paper, some accounts will find all individuals forming the group liable. ${ }^{22}$ When this is the case, we have reason to think that corporate choice 'undermines luck.' Going back to our example, suppose A and B were democracies, and A squandered all its natural resources, ending up, as a result, with less self-determination than B. Suppose, further, that the cause of the squandering are 'sloppy' structures for decision-

\footnotetext{
20 Authorization is not the only condition for distributing liability internally; associative ties, contribution, or benefit would also work; see Pasternak (2013).

${ }^{21}$ This is so (i.e., A should absorb the costs) not only when the actions of B give rise to costs for another agent $\mathrm{C}$, but also when the actions of $\mathrm{B}$ give rise to costs for $\mathrm{A}$. What interests us here is when the latter is the case.

22 This is not to say that they will all be equally liable. The internal distribution of liability is a separate issue (Pasternak, 2011).
} 
making. ${ }^{23}$ Because of this, it would be hard to track responsibility for the outcome (loss of self-determination) back to any individual choice or aggregate choice. Lacking an account of corporate choice, we would not have the theoretical resources to attribute responsibility for the outcome to an agent and would therefore think the inequality between $\mathrm{A}$ and $\mathrm{B}$ is the result of bad luck, and therefore unjust. But insofar as we think rewarding sloppiness is undesirable, the corporate account has the advantage of assessing this situation as not unjust. This is because it would still assign responsibility to the group-agent for the sloppy decision-making structures it licenses and in a second degree to the citizens for their authorization ${ }^{24}$ to such a licensing on account of their democratic membership. This gives us a pro tanto reason to hold the entirety of its citizens liable for A's choice, in which case the inequality between $\mathrm{A}$ and $\mathrm{B}$ could not be unjust.

This section has added plausibility to our initial intuition that extending the luckist-claim to include corporate choice allows us to identify injustices that on the narrow interpretation of the claim would otherwise go undetected. In conclusion, we point out that rendering the LE principle sensitive to corporate choice could, in most cases, lead to identifying the same injustices as when LE is sensitive only to individual choice. However, we should not be too quick in dismissing the extension as redundant, and this is for the simple reason that we

\footnotetext{
${ }^{23}$ This is an adaptation of a real-world case discussed by List and Pettit (2011, p. 167).

${ }^{24}$ See fn. 21 for alternative conditions for the distribution of responsibility.
} 
would have no other way of verifying this possibility than to actually include corporate choice into LE.

\subsection{Re-casting the Scope of Luck Egalitarianism}

In this paper, we have challenged Lippert-Rasmussen's restriction of the scope of LE to individuals. Focusing on the two components of the LE principle we have shown that (in)equality between groups matters non-instrumentally when we recognize that collective goods are included in the metric of equality. This is because if such goods are to be equally distributed at all, they can only be distributed between groups. Turning to the luckist-claim, we have identified two different understandings of group-choice and argued that when LE is sensitive to corporate choice, our assessments of injustice become more nuanced and sophisticated.

The extension of both components of LE to groups, in addition to individuals, expands the possible interpretive combinations of the principle and of its scope as shown in Table 2. Of these possible combinations, Lippert-Rasmussen considers (a) and (b), only to reject the latter. However, we have shown that restriction to be problematic, and that any serious treatment of the question of scope should discuss the other four possible combinations. ${ }^{25}$

\footnotetext{
${ }^{25}$ Our own treatment is partial since we have not discussed (c) for space limits. Let us only note that the conclusions we draw about (f) should in principle also hold for (c). This means that even if Lippert-Rasmussen rejects our claim that group inequality matters, his restriction of the scope of the luckist-claim to individual choices is unwarranted without a treatment of corporate choice.
} 
Let us emphasize that our argument was aimed at expanding LE to the group-level rather than dismissing its application at the individual-level; we think that both group-inequality and corporate choice matter in addition to individual inequality and choice. Of course, this raises the question of how trade-offs between LE applied to individuals and LE applied to groups should be resolved; for example, when the application of both (a) and (d) involves contradictory assessments of injustice. Note, however, that our discussion already provides a way of addressing this issue since it shows that the reason for concern with either inequality is the same; the goods in question are goods that individuals care about noninstrumentally. So, if such conflicts arise, they arise as conflicts about the different weight that individuals attach to the goods within the distribuenda.

Table 2. The Scope of the LE Principle Revised.

\begin{tabular}{|c|c|c|}
\hline \multirow[b]{2}{*}{ Scope of the Luckist-Claim } & \multicolumn{2}{|c|}{ Scope of the Equality-Claim } \\
\hline & Individuals & Groups \\
\hline Individuals & $\begin{array}{l}\text { (a) B etween individuals } \\
\text { individual choice }\end{array}$ & $\begin{array}{l}\text { (d) Between groups } \\
\text { individual choice }\end{array}$ \\
\hline Groups & (b) & (e) \\
\hline Groups & $\begin{array}{l}\text { (c) Between individuals } \\
\text { corporate choice }\end{array}$ & $\begin{array}{l}\text { (f) Between groups } \\
\text { corporate choices }\end{array}$ \\
\hline
\end{tabular}

As we have mentioned at the beginning of the paper, we think that the line of reasoning we have presented could have interesting implications for the position LE occupies in the global justice debate, which we are only going to sketch by way of conclusion. In discussing 
the geographical scope of LE, Lippert-Rasmussen takes cosmopolitanism to follow straightforwardly from the LE principle. However, one implication of our argument would be that of introducing an internationalist ${ }^{26}$ LE principle requiring distributive equality among states. This is so if we are right that there are collective goods that matter for justice and that can only be held by political communities (we have used democratic self-determination as an example). Our discussion of corporate choice could also undermine a straightforward cosmopolitan application of the principle as in those cases where states can be held responsible for sloppy decision-making procedures and their citizens may be asked to shoulder the related losses. $^{27}$

Finally, we should point out what we consider an important contribution of our argument, that of the novel role which the currency of justice could play in deciding whether a cosmopolitan or internationalist principle applies. Disagreements of this kind often depend on different accounts of the grounds of justice. However, our reflection above about trade-offs suggested that settling the conflict will depend on the different weight individuals will give to the

\footnotetext{
${ }^{26}$ In line with its use in the most recent global justice literature (Sangiovanni, 2007), we use internationalism to describe a position that focuses on which obligations of justice states rather than individuals have towards one another.

27 Note that this should not apply to citizens of, for example, corrupt and undemocratic regimes as the connection between the citizens and their state is not the right connection to justify distributing responsibility downwards. Also note that we are here focusing on the LE principle; there may be other justice-related reasons to oppose such conclusions.
} 
distribuenda concerned; in this case, on how much they value collective self-determination more than individual wealth.

Acknowledgements Earlier versions of this paper were presented at the Michs Seminar of the Hoover Chair at UCLouvain, the Political Theory PhD Workshop at University College London, the Justice Everywhere Seminar at the University of Newcastle. We thank their audiences for the stimulating discussions. Special thanks are owed to Avia Pasternak and Peter Jones. We are grateful to the editors for their written comments on previous drafts of the paper and two anonymous referees for their feedback. 

